\title{
A RELAÇÃO DE PODER E A ORDEM DO DISCURSO NO ROMANCE BALADA DE AMOR AO VENTO DE PAULINA CHIZIANE
}

\author{
Néstor Raúl González Gutiérrez ${ }^{1}$
}

\section{RESUMO}

O presente artigo tem como objetivo analisar e refletir a relação do poder e a ordem do discurso no romance Balada de Amor ao vento de Paulina Chiziane e sua relação com as teorias contemporâneas francesas de Michael Foucault, indagando sobre a relação entre o poder e as formas de legitimar o controle do discurso entre a realidade retratada do Moçambique Pós-colonial. Assim como o encontro entre o poder e a variante de gênero, raça/etnia e corpo. A relação entre o feminino e sua sujeição ao discurso ligado à tradição religiosa e cultural que permeia a nação. Discute-se sobre a participação da mulher na sociedade africana e a poligamia como forma vigente de tradição das tribos do sul de Moçambique e o encontro entre a dicotomia tradição/sujeição, poder/gênero em contextos patriarcais e de manutenção do machismo como discurso vigente da contemporaneidade. Analisa as formas de tradição das sociedades de discurso como eixo articulador de disciplinarização do corpo e do comportamento social ligada à representação de homem e mulher e de masculino e feminino. $\mathrm{O}$ trabalho é dividido em três tópicos que nortearão a compreensão do leitor, começando com uma breve biografia da autora, seguindo da articulação da sua obra com a teoria foucaultiana e a obra "A ordem do discurso" para assim continuar com a relação e interligação teórica dos dois autores. Finalizando-se, portanto, com a reflexão do contexto africano e os discursos vigentes de repressão e de controle no feminino, a análise entre a legitimação do poder e sua evidência na obra a ser comparada. Para sua elaboração, se fez necessária a pesquisa bibliográfica de autores como CHIZIANE (2003), FOUCAULT (1996), MACEDO (2007) MATA (2000) SANTANA (2005), que questionam a relação de poder em contextos africanos e a reflexão de fenômenos que instigam o poder e o controle sobre a mulher.

Palavras-Chave: Poder. Discurso. Literatura Africana. Mulher.

\footnotetext{
${ }^{1}$ Mestrando em Letras: Estudos Culturais de Literatura Comparada de Língua Portuguesa. Universidade de Marília - UNIMAR. Bolsista CAPES/PROSUP. Aluno especial do Programa de Pós-graduação em Estudos Comparados de Literaturas de Língua Portuguesa Especialista - FFLCH/USP. Especialista em LIBRAS, tradução interpretação, docência e proficiência (FATERN) e Especialista em Ensino de Língua Espanhola. E-mail: gonzalez2n@gmail.com
} 


\section{ABSTRACT}

This article aims to analyze and reflect the power relations and the order of discoursein the romance "Balada de Amor ao Vento" of Paulina Chiziane and its relationship to the French contemporary theories of Michel Foucault, inquiring about the relationship between power and forms to legitimize the discourse of control between the depicted reality of Post-colonial Mozambique. We also analyze the encounter between power and the variant of gender, race/ethnicity and body, as well, the relationship between women and their subjection to the discourse on the religious and cultural tradition that pervades the nation. It is discussed the participation of women in African society and polygamy as the current form of the tradition of the tribes of southern Mozambique, and the encounter between the dichotomy tradition / bondage, power / gender in patriarchal machismo and maintenance contexts as current discourse of reality at present. It is analyzed forms of tradition of discourse societies as its central theme of disciplining the body and social behavior linked to the man and woman and representation of male and female. The work is divided into three topics which will guide the reader's understanding, beginning with a brief biography of the author, following the joint of his work with Foucault's theory and the text "The discourse on Language" so as to continue the relationship and theoretical interconnection in both authors. Finishing up, therefore, with the reflection of the African context and the prevailing discourses of repression and control in the female, the analysis of the legitimacy of power and highlights the work to be compared. For its elaboration, it was necessary the bibliographic research on authors such as CHIZIANE (2003), FOUCAULT (1996), MACEDO (2007), MATA (2000), and SANTANA (2005), who question the relationship of power in African contexts and the reflection of phenomena instigating the power and control over women.

Keywords: Power. Discourse. African Literature. Woman. 


\section{Introdução}

"O poder é como o vinho. No princípio confunde, transtorna, quase que amarga; pouco depois agrada, e, no fim embriaga" (CHIZIANE, 2003, p. 50).

A literatura africana de língua portuguesa tem ganhado espaços em território brasileiro através da lei 10.639/2003 que obriga as instituições ao ensino e difusão da literatura africana no currículo escolar.

O estudo da literatura ajuda na compreensão de novos mundos e novas realidades, pois através das linhas pode-se identificar questões políticas, culturais e sociais do lugar de autoria e da forma de narração, ampliando as formas de concepção do espaço e tempo e aproximando as realidades por meio da leitura e interpretação de romances, contos e histórias que protegem e conservam a tradição cultural.

No caso particular, e sabendo da importância do estudo aprofundado de temas atuais, e aproximando o continente africano à realidade contemporânea, se faz necessário estudar a dicotomia entre poder e gênero como dispositivos que determinam comportamentos, distribuições e hierarquizações que impedem ou coagem a participação ou que modelam e disciplinarizam as formas de participação e os atos de fala dos emissores.

Este trabalho abordará temas relacionados à ordem do discurso no romance Balada de Amor ao Vento de Paulina Chiziane e seu contraste com as teorias contemporâneas de Michael Foucault.

O trabalho é dividido em três tópicos que nortearão a compreensão do leitor, começando com uma breve biografia da autora, seguindo da articulação da sua obra com a teoria foucaultiana para assim continuar com a relação e interligação teórica dos dois autores. Finalizando-se, portanto, com a análise entre a legitimação do poder e sua evidência na obra a ser comparada. 


\section{Paulina Chiziane}

Escritora moçambicana, nasceu na província de Gaza no dia 4 de julho de 1955. Filha de mãe camponesa e de pai operário. Aos seis anos muda de cidade, saindo da zona rural para se instalar em Lourenço Marques, atual Maputo, capital de Moçambique. Começou o curso superior de Linguística na Universidade Eduardo Mondlane, mas não concluiu. Atualmente vive na Zambézia, uma província na região centro de Moçambique, ao norte de Maputo.

Militante política e integrante do Frente de Liberação de Moçambique (FRELIMO) durante a juventude fez dela uma mulher lutadora e preocupada com interesses sociais, fator que seria introjetado na sua produção escrita. Anos mais tarde e depois da independência do país, em 1975, dedica-se à escrita e a narração de obras literárias.

O mundo literário reconhece-a como escritora, mas ela se considera uma contadora de histórias, arte que aprendeu da sua avó em volta da fogueira. Sua autoria traz à discussão a consolidação de Moçambique desde uma visão histórica, cultura, social e política através da narração de vivência em tempos difíceis, sendo a mulher a protagonista na maioria das suas obras. Tornou-se a primeira mulher moçambicana a publicar um romance quando lançou o seu primeiro livro intitulado Balada de amor ao Vento, em 1990. Logo depois surgiriam romances como Ventos do apocalipse (1995), O Sétimo Juramento (2000), Niketche. Uma história de poligamia (2002), O Alegre Canto da Perdiz (2008) e seu último livro, As Andorinhas (2009).

Sua produção coadjuva processos de ressignificação e contribui na formação e consolidação de uma memória cultural através de seus escritos, salientando que o exercício de escritura romanesca em Moçambique está em processo de formação, visto que:

Faz parte da formação do romance em Moçambique uma profunda preocupação e discussão sobre problemas políticos, assim como sobre o romance como um gênero da escrita por excelência que não se confunde com nenhum outro gênero anterior, e cuja abertura tem uma capacidade plástica de assimilar procedimentos de outras artes e campos do conhecimento. Questão problematizada pelo fato de ser o romance capaz de incluir a oralidade, levantando nesse ponto uma contradição fundamental. Transformações ocorridas no interior do gênero romanesco, quando se trata de estudá-lo sob a 
perspectiva da história da política, trazem suas marcas de diferença, mas também de continuidades no continente africano, cujas narrativas têm, de modo inalienável, o comprometimento com a vida social (MACÊDO, 2007, p. 55).

Nas suas obras, Chiziane vem conseguindo transmitir por meio das suas personagens as vivências das mulheres em uma sociedade póscolonial e evidenciar questões relacionadas ao gênero e ao poder que continuam vigentes em Moçambique.

\section{Balada de Amor ao Vento e sua relação com as teorias foucaultianas}

Michael Foucault na sua obra "A ordem do discurso", texto apresentado na aula inaugural no Collège de France, pronunciada em 2 de dezembro de 1970, menciona que o desejo e o poder consolidam os sistemas de exclusão, mas para que sejam efetivados, existem procedimentos externos e internos, sendo a interdição, o silêncio e a vontade da verdade pertencente ao primeiro, e o comentário, o autor e as disciplinas, ao segundo, permitindo o controle do discurso.

Em "Balada de Amor ao Vento", primeira produção escrita em prosa de Paulina Chiziane, narra a história de Sarnau, uma mulher moçambicana que, através da narração em primeira pessoa, exterioriza um discurso de opressão marcado pelo sofrimento e abandono causados pelo desamor e pelas experiências da dicotomia culturatradição e poder que, em palavras de Inocência Mata, consolidam "uma memória individual que se confronta com os ditames de uma sociedade tradicionalista" (Mata, 2000).

Simultaneamente, de acordo com as teorias de Fiorin (1996, p. 31-35), na obra "As astúcias da enunciação: As categorias de pessoa, espaço e tempo", a personagem usa da macro temporalidade, considerando que existem duas formas temporais sendo uma da enunciação e a outra do enunciado, constante em toda a obra da autora.

A história transcorre em um Moçambique consolidado do encontro entre a força de opressão da colonização, a instrução militar dominada por um discurso de controle, repressão e autoafirmação, sendo o discurso religioso evidente na obra, através dos mecanismos de 
disciplinarização e de controle sobre o corpo e sobre a mulher como figura reprimida da sua sexualidade. Um espaço onde a poligamia se converte no eixo articulador da cultura e controlador das manifestações religiosas, políticas e sociais.

Sarnau, representada como uma mulher sonhadora e trabalhadora, disciplinada e obediente, sendo relacionada com os grupos sociais marginalizados que garantem a ordem econômica e política de uma nação cuja participação, na maioria das vezes, deverá ser submetida e limitada às normas e as leis que são determinadas pelo discurso.

Sarnau, o homem é o Deus na terra, teu marido, teu soberano, teu senhor, e tu serás a serva obediente, excrava, dócil, sua mãe, sua rainha. Vacas caminham, lesmas, para o sacrifício; as cabras ruminam a última érva; galos e galinhas berram na sua despedida ao sol, prepara-se o casamento do filho do rei, Sarnau, o teu homem é o teu senhor. Se ele, furioso, agredir o teu corpo, grita de júbilo porque te ama (CHIZIANE, 2003, p. 23).

No encontro afetivo entre Sarnau e $\mathrm{Mwando}^{2}$, encontramos a tensão causada no embate entre duas formas de subjetivação do discurso que modulam e modificam o pensamento dos seus seguidores, lembrando que Foucault nas suas teorias, reconhece quatro instituições disciplinadoras e moduladoras dos discursos, sendo elas: a escola, a prisão, a clínica e a igreja, sendo esta a convergência entre a relação discurso, poder e ação.

Vou casar-me brevemente com uma rapariga que os meus pais escolheram para mim.

- Mas isso não é problema - disse (Sarnau) entre lágrimas. Eu aceito ser a segunda mulher, ou terceira, como quiseres. Se tivesses dez mulheres eu seria a décima primeria. Mesmo que tivesses cem, eu seria a centésima primeria. O que eu quero é estar ao teu lado.

-Sarnau o teu desejo não pode ser realizado. Nunca serás minha mulher, nem a segunda, nem a terceira, nem centésima primeira. Eu sou cristão e não aceito a poligamia. (Idem, p. 29)

\footnotetext{
${ }^{2}$ Sarnau conhece a Mwando na festa de circuncisão. Filho de Rungo, seminarista que abandona sua vocação. No acontecer da história e pela relação com Sarnau, ele tornase fugitivo da lei e na necessidade de subsistência decide ser pescador. A personagem evidencia o processo de escravatura sometido pelos portugueses no seu processo de colonização.
} 
Neste caso particular, Sarnau representa a doutrinalização oriental, produto da exploração e colonização do oriente em território africano sob a transmissão e preservação de pensamento islâmico subsaariano e a preservação da poligamia como forma de vitalização e empoderamento do discurso do homem e da masculinidade sobre as formas de expressão e de representação social.

Em paralelo, Mwando concebe a fé cristã e o catolicismo como resultado da colonização portuguesa e a imposição de valores e discursos hegemônicos da igreja por meio da exclusão e da abolição do pensamento e do distanciamento do discurso no nativo nas tentativas de embraquecimento das culturas e das lógicas discursivas impostas pelo colonizador, deixando claro que o discurso está imerso dentro de uma ordem social, e das condições de interdição sendo codistribuído segundo a classe, gênero, raça e etnia e que, neste caso, prevaleceria a vontade de saber do homem frente àquela mulher negra, iletrada e submissa.

Seguindo este raciocínio Foucault (1996) propõe que:

Ora, a pertença doutrinária questiona o sujeito que fala e, um
através do outro. Questiona o sujeito que fala através e partir do
enunciado, como provem os procedimentos de exclusão e os
mecanismos de rejeição que entram em jogo quando um sujeito
que fala formula um ou vários enunciados inassimiláveis; a
heresia e a ortodoxia não derivam de um exagero fanático dos
mecanismos doutrináveis, elas lhe pertencem
fundamentalmente.

Eis, assim, como o processo doutrinário e as leis e princípios que compõem o discurso serão legitimados no enfrentamento entre outras formas de pensamento, entre o impasse e confronto desses ideais, mas que sempre prevalecerá os valores intrínsecos que nutrem dito discurso. Quando os discursos enfrentados não são articulados, o resultado será a tentativa de sujeição do outro nas formas de conceber o discurso ou a exclusão e rejeição como forma de proteger os princípios que compõem esse discurso, caso evidenciado na rejeição de Mwando e a união com Sumbi, uma moça católica que defende o discurso do catolicismo e a monogamia como forma legítima da união marital. 
Assim como o louco é isolado da sociedade por não sujeitar-se ao discurso vigente, o suicídio toma valor na tentativa de rejeição, de silêncio e como forma de protesto que interliga a relação de poder sujeito como formas de dessubjetivação que contraria esse discurso. No texto, após Sarnau perceber sua desarticulação com o pensamento de Mwando e por não dominar as leis que conformavam o discurso do outro, ela decide partir dessa subjetividade e rejeitar tanto o seu posicionamento como do outro, resultando no seu suicídio como lógica transgressiva das estruturas do poder e do discurso.

O Lago subiu-me até às orelhas, adeus tudo, adeus Mambone, adeus Mwando, adeus. Avancei mais, e de repente senti o medo a sufocar-me o peito, gritei, quis dar volta atrás, lutei com viva força mas as águas engoliram-me, e só consegui erguer o braço num gesto de adeus e desespero (CHIZIANE, 2003, p. 32).

Nessa negação de ser dominada pelo discurso, a personagem exclui e rejeita toda e qualquer estrutura discursiva, tomando como decisão a desarticulação desses parâmetros e a sua anulação como sujeito partícipe do desejo de poder. Um suicídio que transforma seu destino e que simboliza uma ruptura na sujeição dos discursos para se transformar na opressora perante a sociedade e sua nova posição social. Um acontecimento que marcaria não só seu pensamento senão o direcionamento de novas práticas de ter e manipular o controle, o poder e seus status como futura rainha de Mambone.

[...] esta vida de soberana dá-me prazeres novos, Pelas manhãs percorro o mar verde dos campos na tranquilidade do poder, ostentando sobre as gentes a vaidade de ter triunfado sobre todas as mulheres da minha tribo (Idem, p. 49).

Salienta-se que, em definições foucaultianas, o acontecimento:

[...] não se trata, de um bem entendido, nem da sucessão de instantes no tempo, nem da pluralidade dos diversos sujeitos pensantes; trata-se de cesuras que quebram o instante e o dispersam numa pluralidade de posições e de funções possíveis" (FOUCAULT, 1996).

A cobiça e o desejo de poder fluem nas suas veias, e o controle das novas formas discursivas transforma-se no seu anseio de exercer o poder perante seus novos subordinados, escalando de forma contundente e deixando os últimos lugares para chegar ao primeiro na 
sua condição social, discursiva e de poder, pois uma jogada da vida a transformaria na primeira esposa de Nguila, o rei de Mambone pela eleição seletiva da atual rainha

"[...] nunca sonhei ser a primeira esposa do herdeiro, mas agora só penso em ser rainha. Cada vez que me aproximo da velha, excito-me, e desejo ardentemente que a sua morte seja breve para herdar os grandes braceletes de ouro que ela usa nos braços e nos pés". (CHIZIANE, 2003, p 50).

A poligamia como resultado do poder disciplinar, dada pelas estruturas discursivas da religião e da cultura vigente na história, transforma o cenário em lutas de poder e de hierarquização de classe como forma de controle e restrição da participação da mulher na sociedade machista, prevalecendo a supremacia do homem como fonte de controle da sua sexualidade e como administrador do seu prazer, ressaltando que Foucault (1987) menciona dito adestramento como:

O poder disciplinar é com efeito um poder que, em vez de se apropriar e de retirar, tem como função maior 'adestrar' ou sem dúvida adestrar para retirar e se apropriar ainda mais e melhor. Ele não amarra as forças para reduzi-las; procura ligá-las para multiplicá-las e utilizá-las num todo. Em vez de dobrar uniformemente e por massa tudo o que lhe está submetido, separa, analisa, diferencia, leva seus processos de decomposição até as singularidades necessárias e suficientes [...] A disciplina 'fabrica' indivíduos; ela é a técnica específica de um poder que toma os indivíduos ao mesmo tem como objetos e como instrumento de seu exercício (Idem, p 153).

Considerando a herança como forma de controle e como mecanismo de preservação do desejo de poder, Sarnau dá a luz a gêmeas, que desde o momento do nascimento recaem nelas as estruturas que permeiam o discurso e a impossibilidade de usufruir dele pelo fator de serem subalternas ao poder masculino.

Situação que desencadeia um afastamento do seu marido Nguila e a converte em uma mulher que, sendo a primeira esposa, se transformará na subalterna de Pathi (a quinta esposa na hierarquização de ordem cronológica e de status do casamento) como transposição e ordem do poder.

$\mathrm{Na}$ tentativa de entrar novamente nas regras que consolidam o discurso, ela decide engravidar para, desse modo, dando-lhe um filho 
homem que favoreceria o seu poderio em situação posterior quando este se tornasse o herdeiro legítimo da primeira esposa e assim poder governar.

No entanto, o rei sempre a rejeita, “[...] passam já dois anos que eu espero a minha vez e ele não vem. Quando argumento, vomita-me um discurso degradante que não ouso repetir" (Idem, p. 78), mas que numa situação de sagacidade, Sarnau ao se reencontrar com Mwando, que a engravida e, em uma noite de encontro marital com o rei, ela o faz acreditar que este novo varão é seu legítimo herdeiro.

Para que um discurso seja legitimado, cada sujeito deverá conhecer e respeitar as normas que nutrem esse discurso, caso contrário a punição entra como forma de modificação estrutural e de disciplinarização das paixões e das condutas que ameaçam a ordem e a harmonização das leis estabelecidas, repercutindo nos encontros clandestinos entre Sarnau e Mwando que levariam ao fenômeno diaspórico forçoso como forma de refúgio e preservação da vida perante as normas que permeiam o discurso.

A mudança de espaço faz que o sujeito se libere momentaneamente da opressão e da subordinação, mas não o faz fugir dos dispositivos de controle e de disciplinarização impostos na sociedade, fazendo que o desejo de exercer o poder e a tentativa de preservação do ego masculino e de mandatário, as leis do rei transcendam espaços na busca desse infrator para ser apreendido, punido e castigado por sua indisciplinaridade e por contrariar as regras do discurso. Punição que faz de Mwando um ser frágil e covarde que, priorizando sua vida, abandona novamente a Sarnau grávida e foge para depois ser capturado e escravizado em Angola.

Quinze anos transcorrem e depois de conhecer a força da colonização sobre o território angolano, Mwando volta na busca de Sarnau, situação que simboliza a unificação dos povos na consolidação de Moçambique.

Ressaltando que todo discurso é coadjuvado pela experiência e pelo conhecimento das suas estruturas, a união entre Mwando e Sarnau se faz efetiva quando a tensão das forças dos discursos converge na sujeição e o conhecimento do discurso do outro como forma de apropriação e de nova subjetivação, resignando-se Sarnau que o 
discurso monogâmico, poligâmico ou de qualquer forma de união afetiva trará sempre uma complicação à mulher.

A poligamia tem todos os males, lá isso é verdade, as mulheres disputam pela posse do homem, matam-se, enfeitiçam-se, não chegam a conhecer o prazer do amor [...], Ter o marido por turnos dormindo aqui e ali, noite lá, outra acolá e, quando chega o meio-dia e prova a comida da mulher de quem não gosta, diz logo que não tem sal, que não tem gosto. Quando à noite a mulher reclama, diz que a cama cheira a urina de bebe e lá se vai furtando aos seus deveres. Com a poligamia, com a monogamia ou mesmo solitária, a vida da mulher é sempre dura. (Ibidem, p.137)

\section{O poder como forma de legitimação do discurso}

A consolidação de Moçambique relembra as diversas lutas sociais e políticas que enfrentaram os nativos na unificação de discursos de exclusão e opressão por parte do colonizador para mudar as estruturas discursivas relacionadas à hierarquização interna das tribos. O texto evidencia uma sociedade oprimida, tendo personagens que caracterizam o controle do poder através da opressão dos seus similares. Um rei que mantém uma ordem social e que exerce sua função ressaltando os costumes culturais e sociais como forma de manutenção cultural da nação.

Embora o país tenha consolidado uma independência como forma de descentralização e autoadministração do poder pelos nativos do território moçambicano, salienta-se que discursos de adestramento e disciplinarização continuam vigentes, pois a repressão forma um conjunto de valores na forma de autogarantir a ordem econômica e religiosa que permeiam as realidades africanas e os dispositivos de controle do discurso, dando-lhe credibilidade e permissão ao gênero masculino e as masculinidades como sujeitos agenciadores do discurso, colocando-se na frente das mulheres como colonizadores dos seus corpos e das suas liberdades, assim como os gerenciadores da sua sexualidade.

As regras impostas pela sociedade determinam e restringem os sujeitos que falam, pois "ninguém entrará na ordem do discurso se não satisfazer a certas exigências ou se não for de início, qualificado para 
fazê-lo." (FOUCAULT, 1996, p 37), conformando sociedades de discursos que garantirão a circulação interna dos discursos que eles próprios conservam ou produzem; caso evidenciado na sujeição desse discurso e a prevalência do homem como gerenciador do poder.

As minhas mães, tias, avós, fecharam-me há uma semana nesta palhota tão quente e dizeram que me preparam para o matrimônio. Falam do amor como os olhos embaciados, falam da vida com os corações dilacerados, falam do homem pelas chagas desferidas no corpo e na alma durante séculos, Sarnau fecha a tua boca, esconde o teu sofrimento quando o homem dormir com a tua irmã mais nova mesmo na tua presença, Fecha os olhos e não chores porque o homem não foi feito para uma só mulher. (CHIZIANE 2003, p 44).

Quando as sociedades de discurso garantem a sujeição de seus indivíduos, exaltam o opressor como herói e como gerente vitalizador das disciplinas, convertendo-o em um ritualizador capaz de determinar as formas de agir e de sujeitar aos outros. Foucault (1996, p. 39) identifica este comportamento como ritual de fala, que: "define os gestos, os comportamentos, as circunstancias e todo o conjunto de sinais que devem acompanhar o discurso". Evidenciado no romance no momento em que Sarnau, ainda sabendo do relacionamento do rei com Mayi, não tem mais escolha que obedecer e subordina-se ao sujeito que fala.

Regressei voando, coloquei-me de joelhos perante o meu soberano, baixei os olhos como manda a tradição e disse:

-Diga, pai.

-A água está pronta?

-Sim, Pai.

-Hum, parece que choraste, Morreu alguém?

Arremessou-me um violento pontapé no traseiro que me deixou estatelada no chão. Muito depois voltei à posição inicial. Enviou-me uma bofetada impiedosa que fez saltar um dente. A minha rival assistia a tudo, coroando-me com um sorriso de troça e de triunfo (CHIZIANE, 2003, p. 56).

Questionando sua posição como mulher, ela sai no encontro com a rainha, quem aconselha seguir ditas regras, pois elas desde o nascimento foram enviadas para comprazer ao homem, esperando o retorno do seu marido, que reforçará novamente o ritual de fala e o controle do poder. 
[...] o meu marido está bêbado de morrer, vai torturar-me, este búfalo louco, por Deus"!

-Sarnau estás Zangada?

-Não, Não estou.

-Mas choraste. A bofetada que te dei foi só uma disciplina para aprenderes a não fazer ciúmes (Idem, p. 57).

Como foi mencionada, a poligamia favorece ao discurso masculino como legitimador do poder, como o opressor e como aquele que determina as regras do comportamento. Assim mesmo, garante que todo aquele que não esteja sujeito do discurso deverá ser punido. Momento em que Nguila aciona o dispositivo de controle externo do discurso ao saber que Sarnau tem um relacionamento em segredo com Mwando, contado pela sua quinta esposa Pathi, como forma de preservação das estruturas do discurso e garantir o controle e a vigilância tanto dos infratores como daqueles que tentem burlá-lo. Situação que terminaria na morte das duas mulheres, mas que pela sagacidade de Sarnau, ela consegue fugir desta punição.“[...] Tu e a Pathi morrerão, adeus minha rainha, adeus Pathi. Sou um homem morto, neste momento, e devo defender o meu orgulho" (Idem, p. 100).

Outra forma de poder é evidenciada no encontro de colonizador colonizado, representado por Mwando quando foi escravizado em terras Angolanas, que conhecendo o discurso que legitima o poder do colonizador consegue mexer nas estruturas desse discurso a partir da resistência e mimeses para garantir sua opressão nos oprimidos e que sabendo disso ousa em entrar no catolicismo e se tornar em "o padre Moçambique", sabendo que "O poder se exerce por meio de relações de força, de enfrentamento, de forma que haja sempre possibilidade de resistências". (FOUCAULT, 2004, p. 37)

Finalmente, o romance permite a indagação dos processos de controle e poder, ensinando que todo processo de poder determinará as pretensões que seus emissores impõem, mas antes disso, saber que todo e qualquer discurso permeará e norteará os procedimentos e os dispositivos de controle. Cabe a cada sujeito conhecer os discursos para serem partícipes dele e não sujeitos do controle, da vingança e do poder dele pelo desconhecimento ou pela ignorância de não conhecer as normas que os regem. 


\section{Considerações finais}

Toda e qualquer sociedade será permeada pelos discursos disciplinadores que garantam o adestramento e a sujeição do indivíduo a esse discurso, pois, o ser humano sempre será administrado pelas suas paixões e o desejo de exercer o poder perante algum grupo social ou algum indivíduo que esteja sob sua responsabilidade.

A distribuição de poder em território africano tem favorecido a figura masculina como gerenciador dos dispositivos de controle do discurso, fazendo das mulheres um agente permanente de sujeição e de silenciamento no processo de subjetivação. Cada tentativa de indagar ou questionar o discurso trará formas de punição que garantirão ainda mais a prevalência do discurso atual.

O poder é exercido e multiplicado pelas instituições que conhecem as estruturas, as disciplinas e as formas de governar o poder, fazendo dele um conhecimento absoluto e inquestionável como forma de preservação e de controle dele. Qualquer tentativa de negação ou substituição será fortemente reprimida de tal forma que seus seguidores optarão por resistir ante essas repressões ou sujeitar-se a esse discurso como mecanismo de amenizar o sofrimento causado por ir contra o discurso.

Nas sociedades africanas, e na vigência e manutenção da cultura, da religião e das tradições sócio-políticas, o homem tem se autoproclamado o continuador e dominador dos discursos sociais, sendo eles os executores do poder e a homogeneização do comportamento masculino e feminino, cabendo a este ultimo a sujeição e a subalternação dos sistemas e dos dispositivos da exclusão. Toda manifestação de questionamento, indagação pela mulher destas normas será abolida, reprimida e castigada. 


\section{Referências}

CHIZIANE, Paulina. Balada de amor ao Vento. Lisboa. Editorial Caminho S.A. 2003.

FOUCAULT, Michel. A ordem do discurso. São Paulo, Edições Loyola, 1996.

. Vigiar e Punir. Petrópolis. Vozes, 1987.

. Ética, sexualidade, política. Tradução Elisa Monteiro; Inês Autran Dourado Barbosa. Rio de Janeiro: Forense Universitária, 2004.

MACÊDO, Tania; MAQUÊA, Vera. Literaturas de Língua Portuguesa -Moçambique. São Paulo: Arte \& Ciência, 2007.

MATA, Inocência. Paulina Chiziane: uma coletora de memórias imaginadas. In: Metamorfoses. Lisboa: Edições Cosmos, 2000.

SANTANA, Patrícia. O super-homem calcificado no éden da praça: caminhos da tradição em Nietzsche. Artigo publicado (Mestranda em Letras e Ciências Humanas) UNIGRANRIO, 2005. 